\title{
Market Premium and Macroeconomic Factors as Determinants of Industry Premium: Evidence from Emerging Economies
}

\author{
Muhammad Imran $\mathbb{D}^{1,},{ }^{1,2,3}$ Mengyun Wu, ${ }^{1}$ Linrong Zhang, ${ }^{1}$ Yun Zhao, ${ }^{4}$ Noor Jehan, \\ and Hee Cheol Moon iD ${ }^{6}$ \\ ${ }^{1}$ School of Finance and Economics, Jiangsu University, Zhenjiang, Jiangsu 212013, China \\ ${ }^{2}$ Faculty of Management Science, ILMA University, Karachi, Pakistan \\ ${ }^{3}$ Department of Management Science \& Commerce, Alhamd Islamic University, Quetta, Pakistan \\ ${ }^{4}$ Department of Economics and Management, Yuncheng University, Yuncheng 44000, Shanxi, China \\ ${ }^{5}$ Department of Economics, Abdul Wali Khan University, Mardan, Khyber Pakhtunkhwa 23200, Pakistan \\ ${ }^{6}$ Department of International Trade, Chungnam National University, Daejeon 34134, Republic of Korea \\ Correspondence should be addressed to Hee Cheol Moon; hcmoon@cnu.ac.kr
}

Received 16 February 2021; Revised 10 March 2021; Accepted 20 March 2021; Published 12 April 2021

Academic Editor: Baogui Xin

Copyright (c) 2021 Muhammad Imran et al. This is an open access article distributed under the Creative Commons Attribution License, which permits unrestricted use, distribution, and reproduction in any medium, provided the original work is properly cited.

In this study, we examine the equity (industry) premium of seventeen nonfinancial sectors covering sample 306 firms using monthly data from January 2002 to December 2018. Two-stage least square (2SLS) method is applied to estimate the macro-based multifactor model. It is found that the market premium and the interest rate factors are significantly affecting the industry equity premium of all the nonfinancial sectors. However, there exists a positive effect of other macroeconomic variables such as money supply, foreign direct investment, and industrial production which is different for the different sectors based on its nature of product and services they offered. The industries based on their product development which are linked to particular macroeconomic variables have more effect than others such as increase in money supply which cannot increase the sale of pharmaceutical products until needed. Similarly, an interesting insight reveals that industries producing seasonal goods, e.g., food producing, are not very much affected by macroeconomic variables but the change in seasons and similar results also revealed for tobacco industry.

\section{Introduction}

Since asset pricing can be viewed in terms of per share expected discounted cash flows and the required rate of returns, macroeconomic variables that effect future cash flows or required rates of return should also influence asset pricing. Therefore, its impact on historical returns is an important component to study for planning of future investment decision. In the current situation, one of the most contemporary issues in advance corporate finance and financial economics is the magnitude of equity premium in the total returns of an investment. The equity premium is the additional return that investors necessitate from investing in riskier stocks rather than risk-free securities. Equity (risk) premium drives the total expected stock returns and is a key determinant of the cost of equity. In this study, we calculate the sectoral premium by using [1] a method to form each sector portfolio and calculate the sector premium.

Equity risk premium is the essential element of every risk and return model in finance and is a major input into estimating costs of equity and cost of capital in both economics and corporate finance valuation models [2]. In the standard mathematical technique to calculate the equity risk premiums, the researcher used historical returns with the difference in annual returns on stocks and risk-free securities such as bonds and bills over a long time period, comprising the expected equity premium. The investments in risky stocks are expected to produce higher expected returns than 
those investment opportunities which have very low or even no risk. It is usually discussed in the existing literature that the equity risk premium is high in developing markets than in developed countries' stock markets $[3,4]$. This is because investing in emerging markets is usually apparently to be more risky, which has to be rewarded in terms of a high expected return.

Equity risk premium is estimated in many asset pricing models such as APT, three-factor model, and multifactor models [5]. [6] Research work by Markowitz was the first study to lay down the base line for this kind of analysis. Markowitz theory was further developed and constructed into capital asset pricing model (CAPM) by [7-12]. The CAPM has been extensively used by the financial research experts. It is adopted in the portfolio management as a standard of rating the performance of portfolio managers.

The "capital asset pricing model" is explained by the following equation:

$$
E\left(R_{i}\right)=R_{f}+\beta\left[E\left(R_{m}\right)-R_{f}\right]
$$

where $E\left(R_{i}\right)$ is the expected return on industry $i$ where $i=1-17, R_{f}$ is the risk-free interest rate, $E\left(R_{m}\right)$ is the expected return of the market, and $\beta$ is the measure of market risk. Expression in the square brackets is the equity risk premium.

The equity premium has always been under the severe pressure during the period of any financial crises and its magnitude always depends upon the stable market. When the market return decreases, the magnitude of the premium becomes near to zero or even negative. During the Asian financial crisis (1997 Asian economic crises), the volatility in the global stock markets also increased. When equity returns have more volatility, the market systematic risk $(\beta)$ is also more likely to be increased. The stocks having more disclosure to the sources of risk will have more equity price reactions than the rest of the firms. Similarly, scholars study the risk and return relationship in six Asian stock markets which were affected by the 1997 Asian economic crisis. Their conclusions showed that market equity risk $(\beta)$ steadily increased and the expected average returns dropped significantly after the start of the economic crisis and led to considerable drop in the equity premium. Choudhry and $\mathrm{Wu}$ [13] provided a study of the effects of the Asian crisis on the beta of Malaysian and Taiwanese firms. The results show a rise in the systematic risk $(\beta)$ during the economic crisis, especially in the case of Malaysian stock market. Similarly, recently, Bellelah et al. [14] explored how the global financial crises affect the equity premium. Several studies conclude that the financial crises lead to volatility which increases the systematic risk coefficient. Increase in the systematic risk causes increase in the expected rate of return.

The equity risk premium is calculated through two general ways: the use of historical stock market data and the use of estimate for future projections. To calculate the equity risk premium one must know about the market rate of return and the risk-free asset of the particular country. The equity risk premium can be calculated for any time period. However, the best results are generated for longer period of data. The United States capital markets data exist back as late as 1800 s. While calculating the equity premium, one should consider the benchmark market of the country under consideration. A standard practice has been observed while studying the literature that most of the studies cite only the United States and European markets experience. However, the US source remains the most widely used citation. The historical record of data availability exceeded more than 100 years.

1.1. Significance of Pakistan Stock Exchange. KSE100 index is the standard benchmark of the Pakistan Stock Exchange (PSX) to compare price over the period of time to decide the representative of higher market capitalization of the PSX listed companies. Pakistan Stock Exchange is an emerging capital market and studied extensively by both practitioners and academicians [15-19]. They studied different dimensions starting from the performance of stock market, its determinants, and applicability of different financial models. This study is raising question regarding the calculation of sector equity premium and its determinants of nonfinancial listed firms in Pakistan Stock Exchange (PSX). Besides other factors, investment analyst also greatly relies on the equity risk premium while making portfolio asset allocation decision and calculating the cost of equity and equity premium is affected by many variables as well as the time frame of the investments which further agitates the total expected return of assets. In Pakistan, a number of related literature [19-23] among others is available about stock market return, its implications, determinants, and interrelation with global markets. However, as per the best knowledge of the authors, very limited studies have been found on market premium and no study found on firm sector equity premium. In order to reduce this gap in Pakistan Stock Exchange, this research is of the most importance.

1.2. Significance of the Study. Previously, many research studies have explored the effect of economic factors and stock market returns. This study is an effort to investigate the relationship among industry level equity premium and macroeconomic determinants which is scant in the literature. This study will examine the impact of macroeconomic variables on the industry level equity premium. Furthermore, the study has been motivated by a number of factors. In Pakistan, plenty of researches have been done on stock market return, economic growth, and its determinants, for example, Zeeshan et al. [19, 23-25] studied the relationship between macroeconomic variables and KSE100 index and found that GDP, exchange rate, and inflation are positively related to stocked prices while negatively related to interest rate. Similarly, company factors and stock return have also been studied in many stock markets $[2,12,26]$. The previous works done were mostly based on stock return rather than considering an important factor of industry level equity premium. Therefore, there is still room for examining the macroeconomic variables and industry level equity premium. To the author's knowledge, no specific study has been done for estimating equity premium determinants in 
Pakistan and it is also difficult to know about the size of historical equity premium of Pakistani capital market though it is the net return (market return less risk-free interest rate) and one of the main components of total returns.

\subsection{Macroeconomic Factors as Drivers of Equity Premium.} Macroeconomic factors such as interest rate, inflation, industrial production, and other factors severely affect the stock returns which translated into equity premium. The equity premium is lower in economies where the macroeconomic variables are more volatile. Lettau et al. [27] explored that change in equity premium in US capital market is mainly caused by volatility of macroeconomic variables $[28,29]$; these studies examine the relationship among inflation and equity premiums and found very little or no correlation. However, Brandt et al. [30, 31] discussed that positive news about change in inflation rate dominates news about real economic and financial growth in determining risk aversion and risk premiums. They present support that equity risk premiums be inclined to boost if inflation is higher than expected and will decline when it is lower than expected. The latest study by Wang [32] indicates that increase in inflation causes increase in ERP. Kizys and Spencer [33] opined that macroeconomic influence on the US and Japanese stock returns showed a positive relation with industrial production and a negative relation with inflation and interest rate. However, Japanese stocks were negatively related to the money supply, while US stocks had no significant relation. Lamont [34] is of the view that portfolios developed to follow the growth rates of real income (GDP) and consumption and labour income earned abnormal positive expected returns.

Neely et al. [35] explored that inflation rate has strong correlation with changes in risk premium. According to Kizys and Spencer [33], long-term government bonds can explain perception of investors about inflation much clearer than short-term interest rate and also inflation is more influential in long-term investment periods than the short periods. Chou et al. [36] conducted a study related to macroeconomic factors and equity premium which have been done in the developed financial markets. However, the literature available in developing economies such as Pakistan is limited. In the current research, we are considering a set of macroeconomic factors as determinant on firm level equity risk premium in Pakistan. More recently, Imran et al. $[5,37,38]$ conclude that along with economic and financial factors, noneconomic factors also cause volatility of stock return and equity premium. They consider terrorism and political instability in Pakistan as major noneconomic factors of volatility in Pakistan stock market.

1.4. Research Objectives. The study analyses the effects of macroeconomic and sectoral premium of PSX. We are considering seventeen different nonfinancial sectors that how different macroeconomic variables affect the equity premium of different sectors. For this purpose, an extended version of the macro-based multifactor model is used for estimating equity premium which includes the set of macroeconomic variables which are most relevant to nonfinancial sectors. Moreover, we attempt to broaden the techniques used in the previous studies and thus discussed the contribution of this research which is to expand previous analyses of the expected market premium to industry level equity premium.

The following Section 2 presents the detailed literature review followed by model description in Section 3. Section 4 provides the estimated results and discussion, and finally Section 5 concludes the research paper.

\section{Literature Review}

The most popular funds allocation and investment decision were based on mean-variance analysis. Markowitz [6] and Tobin [39] introduced the mean-variance rule. Perhaps, this was the first most used investment allocation tool under any uncertainty in economics and finance. This has been broadly used by academics and investment practitioners in the past. The same mean-variance analysis framework is the base of $[8,9]$ capital asset pricing model (CAPM), which is the cornerstone of today's modern economics and finance and other theoretical models.

According to Damodaran [2], high equity premium is witnessed by many authors but usually their estimates are based on long period of historical data of almost 100 years (Ibbotson associate data bank starting from 1926). Several studies concluded that the equity returns and equity premium could be better for a longer period. As far as the long period is concern, it is obvious that the return will be higher in the long period as compared to the short time period. According to Elton and Gruber [40], equity premium is one of the most significant pillars of modern portfolio theory with the condition that most of the investors are risk averse and like to have return with less risk. Therefore, the investment over the long period produced higher returns. This fact can be supported by literature of Goetzmann and Ibbotson [41]. Elton and Gruber [40, 42] wrote that investors want high return from the less risky investment. However, this could be true to have higher return from less risky investment only if you invest in a bearish trend.

In an equity premium survey report by Fernandez et al., [43] considerable variation in equity premiums across economic analysts within the same stock market was made. In the United States, for example, they recorded that the average equity risk premium across analysts was $5.8 \%$. However, the numbers produced by different academic and economic experts ranged from $3.2 \%$ to $10.5 \%$. More recently, Imra et al. [5, 37, 38] disclosed the noneconomic variables influence the stock market returns and firm level equity premium. The current study analyses the impact of macroeconomic variables on industry-level equity premium to check that which industries are more vulnerable to change in macroeconomic factors. 
2.1. Selection of Variables. The preference of the macroeconomic variables is not random. It is motivated by number of research articles that have investigated the matter in detail and received worldwide appreciation. Roll and Ross [44] investigated macroeconomic influences on stock price (as well as risk premium) and proved that gross domestic product (GDP) and inflation do influence risk premium. Arnott and Henriksson [45] in their research study about historical risk premium in the United States of America pointed out that inflation and GDP growth have had big influence on risk premium value in the USA during 1802-2002. Lettau et al. [27] opined that equity risk premium used the term "macroeconomic risk," which is volatility of the aggregate economy. They pointed out that changes in GDP were the most important factors in economic changes, which in its turn influenced risk premium. Neely et al. [35] also found that inflation rate has strong correlation with changes in risk premium. According to Kizys and Spencer [33], long-term government bonds can explain the perception of investors about inflation much clearer than short-term interest rate and also inflation is more influential in long-term investment horizons than the short one. A study of macroeconomic influences on the US and Japanese stock returns showed a positive relation with industrial production and a negative relation with inflation and interest rate. However, Japanese stocks were negatively related to the money supply, while the US stocks had no significant relationship. According to [36, 46], a set of macroeconomic variables has an effect on stock prices that lead to change in equity premium and translated in total expected returns. Recently, Churchill et al. [47] reviewed 87 research studies on the effect of government expenditure on economic development and growth. In the high income countries, there is negative effect of government expenditure and GDP.

Lamont [34] explored that portfolios developed to follow the growth rates of industrial production, consumption, and labour income to earned abnormal positive returns, while opposite is true with interest rate and inflation. Similarly, Bai [48] developed and proposed a macroeconomic index that explained short-term disparity in future equity returns with more predicting capacity than the historical average returns. A significant cyclical pattern was marked with time-varying macroeconomic conditions.

\section{Model}

3.1. Theoretical Background Framework. The theoretical work relevant to equity premium started since 1952. The earliest theory of risk and return model was capital asset pricing model (CAPM). While extending this tremendous work of Markowitz, the arbitrage pricing theory (APT) came with more good results followed by three-factor model and multifactor model of Fama and French. Similarly, relevant to the different degrees of risk, macro-based and-micro based risk factor models were also developed accordingly. However, there is still room to investigate the industry equity premium and its determinants using macro-based multifactor model.
3.2. Macro-Based Risk Factor Model. We calculate the equity risk premium for sector portfolios rather than market premium as examined in earlier studies. The sector level equity premium differentiates this research from other studies conducted. We extend the macro-based model $[49,50]$ for a set of more relevant macroeconomic variables according to Pakistani scenario and to explore how these macroeconomic variables affect the sector level equity premium in Pakistan's capital market. This will be the first study to be conducted on sector level premium, and we used the modified version of macro-based multifactor model, and can be expressed as:

$$
\begin{aligned}
\left(R_{s t}-R_{f t}\right)= & \alpha_{i}+\beta_{i 1}\left(R_{m t}-R_{f t}\right)+\beta_{i 2}\left(\text { InterestRate }_{t}\right) \\
& +\beta_{i 3}\left(\text { Inflation }_{t}\right)+\beta_{i 4}\left(\mathrm{FDI}_{t}\right) \\
& +\beta_{i 5}\left(\text { MoneySupply }_{t}\right)+\beta_{i 6}\left(\mathrm{GDP}_{t}\right)+\varepsilon_{i t} .
\end{aligned}
$$

The macro-based multifactor model is only used for capturing the impact of macroeconomic variables and equity premium in Pakistan Stock Exchange. Ewijk et al. [51] examined that the equity risk premium tends to increase in more economic volatility and changing of economic policies. The author witnessed negative effect of the interest rate on equity risk premium. This indicates that the total return on stock cannot be calculated by adding a stable equity risk premium to a time-varying short or long-term risk-free interest rate. The risk-free rate of return on equity premium has its own determinants which is partly correlated with the dynamics of the interest rate and equity risk premium.

3.3. Data Collection. There are 654 listed stocks at Pakistan Stock Exchange (PSX) as of December 2018. The focus of this study is on the nonfinancial sectors listed in PSX. It excludes the financial sector of Pakistan. The main reason is that there exists a difference in the financial mix and other regulatory requirements of financial and nonfinancial sectors. This study selected 306 companies from the nonfinancial sectors. The data for the study were collected from Pakistan Stock Exchange (PSX) official website (http://www.kse.gov.pk', business recorder, economic survey of Pakistan, and International Finance Statistics (IFS). The number of firms from each sector is provided in Table 1 in the appendix of this paper.

3.4. Research Methodology. The study uses the assumption of continuous returns for KSE100 index and the asset prices of each firm. The continuously compounded returns formula is expressed as follows:

$$
\text { future value }=\text { present value } \times e^{i n} .
$$

Continuously compounded returns are computed for each asset by using the following formula:

$$
R_{t}=\ln \left(P_{t} / P_{t-1}\right) .
$$


After calculating the returns of KSE100 index and sector's average returns, now the data are ready to calculate each sector equity premium by taking the difference of sector return and risk-free interest rate following the Fama and French [26]; Damodaram [12] method:

$$
E R_{i}=R_{m}-R_{f} .
$$

To analyse our data, we use two-stage least square method.

3.5. Two-Stage Least Square Method. Two-stage least squares (TSLS) is a particular case of instrumental variables regression. As the name suggests, there are two discrete stages in two-stage least squares. In the first stage, TSLS finds the portions of the endogenous and exogenous variables that can be attributed to the instruments. This stage involves estimating an ordinary least square (OLS) regression of each variable in the model on the set of instruments. The second stage is a regression of the original equation, with all of the variables replaced with their instruments. The coefficients of this regression are the twostage least square estimates.

The standard regression model is

$$
y=X \beta+\varepsilon,
$$

where " $y$ " is the " $T$ " dimensional vector containing observations of the dependent variable, $X$ is a $T \times k$ matrix of independent variables, $\beta$ is a k-vector of coefficient, and $\varepsilon$ is a T-vector of disturbances. $T$ is the number of observations and $k$ is the number of right hand side regressor.

The least squares regression coefficient $b$ is computed by the standard OLS formula:

$$
b_{\mathrm{OLs}}=\left(X^{\prime} X\right)^{-1} X^{\prime} y .
$$

Let $Z$ be the matrix of instruments, and let $y$ and $X$ be the dependent explanatory variables. The linear TSLS objective function is given by

$$
\Psi(\beta)=(y-X \beta)^{\prime} Z\left(Z^{\prime}\right)^{-1} Z^{\prime}(y-X \beta) .
$$

Then, the coefficients computed in two-stage least square are given by

$$
b_{\text {TSLS }}=X^{\prime} Z\left(Z^{\prime} Z\right)^{-1} Z^{\prime X^{-1}} X^{\prime} Z\left(Z^{\prime} Z\right)^{-1} Z^{\prime} y,
$$

and the standard estimated covariance matrix of these coefficients may be computed using

$$
\hat{\sum} \mathrm{TSLS}=S^{2}\left(X^{\prime} Z\left(Z^{\prime} Z\right)^{-1} Z^{\prime} X\right)^{-1} X^{\prime} Z\left(Z^{\prime} Z\right)^{-1} Z^{\prime} Y,
$$

where $\oint^{2}$ is the estimated residual variance (square of the standard error of the regression).

The following assumptions must be testified before performing two-stage least square method. The variance of error term for all variables must be homoskedastic, i.e., equal $\operatorname{Var}\left(v_{i j}\right)=\sigma^{2}$. Error terms must be normally distributed, i.e., $v_{i j} \sim N\left(0, \sigma^{2}\right)$.

Model should be properly and correctly defined.
It is assumed that observation should be independent of each other.

It is also assumed that unusual observations, i.e., outliers, is removed from the dataset.

The dataset for the macroeconomic variables and sector premium consists of time series data. The frequency of this dataset is monthly. Two-stage least square (2SLS) method is used for the analysis and estimation for this dataset.

\section{Empirical Analysis of Macroeconomic Variables}

Table 2 contains the summary statistics for the macroeconomic variables used in this study, which may help in the interpretation of the coefficient estimates by providing the scale of the relevant variables (see Appendix Table 2).

Table 3 in the appendix contains the summary statistics of the market premium of each sector used in this study (see Appendix Table 3.

Table 4 in the appendix shows the results of the correlation matrix which indicate that there is no serious correlation issue. The sector equity premium is considered as dependent variable. To assess the normality of dependent variable, i.e., industry equity premium, Kolmogorov-Smirnov test is applied. The results are presented in Table 5 (in appendix). The results demonstrate that $p$ value of Kolmogorov-Smirnov test is insignificant which suggests that sector premium is normal. The same normality trend is also observed by constructing a histogram.

4.1. Sectorwise Estimated Results. To estimate our model, we have applied two-stage least square (2SLS) method. The estimation of model is not appropriate by using the simple ordinary least square method as the problem of possible endogeneity of the variables can cause to be the least squares estimators biased and contradictory. Endogeneity is expected to occur mainly due to reveres causality between the independent variables such as inflation and money supply; these likely same nature variables are therefore likely to be correlated with the error term. To find reliable parameter estimates in panel data, we apply two-stage least square estimation technique [52]. This technique is based on the standard of variables which are used as instruments under the theoretical assumption that, although there may be correlation between explanatory variables and the error term, such correlation does not exists between the lagged variables and the error term (rather than using changes in lagged $U_{-}$as instruments, we can use lagged levels of $U_{-}$. For example, choosing $\left(U_{-}, 6_{-}, U_{-}, 6_{-}\right)$_ instrument at time $t$ is no less efficient than the procedure that uses $\left(\Delta U_{-}, 6_{-}\right)$, as the latter is a linear combination of the former $52)$.

To overcome for the likelihood of cross-sectional hetroskedasticity, which also affects the effectiveness of the estimators and the strength of the hypothesis testing and inference, the models are estimated by using white crosssectional standard errors and covariance. The correction for 
hetroskedasticity improves the statistical significance of the regressors.

The industrywise estimated results are discussed as follows. These results are good for the practical implication for each sector analysis. The company management can take necessary measures for any change in the macroeconomic variables. On the other hand, the investors can change their investment decision apropos to certain change in the monetary and fiscal policy which leads to change in the macroeconomic variables. Some variables affect one industry different from others; therefore, this analysis is very important in that respect. The interpretation of estimated results is presented below.

4.2. Automobile and Parts. Table 6A(refer to Table 6, in the appendix; 6A refers to column A in "Table 6.". Each column presents separate sector results of this study) presents the estimated results of automobile sector with macroeconomic variables. The estimated results are according to theoretical expectations. The coefficient on market premium is positive and statistically significant which indicates that one percent increase in market premium will increase equity risk premium in automobile sector by 0.99 percent. This result is consistent with [26]. The statistically significant negative coefficient on T-Bill rate indicates that one percent increase in interest rate decreases equity risk premium in the automobile sector by 0.03 percent. Also, the negative and statistically significant coefficients of inflation indicate that one percent increase in inflation causes 0.07 percent decrease in firm level equity premium. The statistical significant value of industrial production is consistent with the theoretical expectations that increase in industrial growth causes increase in the equity risk premium. This indicates that one percent increase in industrial growth will increase equity risk premium in the automobile sector by more than 0.12 percent. The coefficient of money supply variable is negative but statistically insignificant, which implies that money supply does not affect equity risk premium in the automobile sector. These results are consistent with result by Ferreira [53]. Just like money supply, the effect of foreign direct investment on equity risk premium is also statistically insignificant. It implies that FDI does not affect equity premium in the automobile sector (Appendix Table 6).

The value of coefficient of determination $\left(R^{2}\right)$ indicates that more than 42 percent variation in the model is explained by the explanatory variables. Similarly, the value of adjusted$R^{2}$ implies that more than 40 percent variation in equity risk premium is explained by the explanatory variables. The value of F-statistics is highly statistically significant, which indicates that the model fitted the data well. The value of the Durban Watson (DW) test is close to the standard value of 2, which implies that there is no serious problem of autocorrelation in the data. To verify the autocorrelation issue, we have also applied Lagrange Multiplier (LM) serial correlation test. Unlike the DW-statistic for AR(1) errors, the LM test may be used to test for higher order auto regressive moving average (ARMA) errors and is appropriate whether there are lagged dependent variables or not. Therefore, we recommend its use (in preference to the DW-statistic) whenever we are concerned with the possibility that our errors exhibit autocorrelation. The null hypothesis of the LM test is that there is no serial correlation up to lag order $p$, where $p$ is a prespecified integer. The local alternative is $\operatorname{ARMA}(r, q)$ error, where the number of lag terms $p=\max (r$, $q)$. Note that this alternative includes both $\operatorname{AR}(p)$ and $\operatorname{MA}(p)$ error processes so that the test may have power against a variety of alternative autocorrelation structures. The LM test statistic is asymptotically distributed as a $\chi^{2}(p)$ and is computed as the number of observation $(n)$ times the (uncentered) $R^{2}$. From the test regression, i.e., $\chi^{2}(p)=n \cdot R^{2}$, insignificant value of LM statistics also confirms the absence of autocorrelation problem. Moreover, to test the validity of the instrument, the J-statistics, which is also as the Sargan statistic, for over-identifying restrictions is used. Under the null hypothesis that the over-identifying restrictions are valid, the Sargan statistic is distributed as $\gamma(p-k)$, where $k$ is the number of estimated coefficients and $p$ is the instrument rank. The high insignificant $p$ values of the J-statistics indicate that the instruments are valid.

4.3. Engineering Sector. Table $6 \mathrm{~B}$ in the appendix presents the estimated results of engineering sector with macroeconomic variables. The estimated results are consistent with the theoretical expectations. The coefficient on market premium is positive and statistically significant which indicates that one percent increase in market premium will increase equity risk premium in the engineering sector by 0.60 percent. The statistically significant negative coefficient on T-Bill rate indicates that one percent increase in interest rate decreases equity risk premium in the engineering sector by 0.04 percent. The coefficient of inflation is not according to expectation. Theoretically, the impact of inflation on equity returns is negative. However, in our results, the coefficient is positive but statistically insignificant. Just like inflation, the coefficient of money supply, industrial production index, and foreign direct investment are statistically insignificant, which implies that these variable do not affect equity risk premium in the engineering sector.

The value of coefficient of determination $\left(R^{2}\right)$ indicates that more than 30 percent variation in the model is explained by the explanatory variables. Similarly, the value of adjusted$R^{2}$ implies that more than 27 percent variation in equity premium is explained by the model. The value of F-statistics is highly statistically significant, which implies that the model fits the data well. The value of the DW test is almost equal to the desired value of 2 , which shows that there is no autocorrelation problem in the data. Insignificant value of LM statistics also confirms that there is no serious problem of autocorrelation in the data. Moreover, the high insignificant value of J-statistics indicates that the instruments used are valid.

4.4. Beverages. Table $6 \mathrm{C}$ in the appendix presents the estimated results of beverages sector with macroeconomic variables. The estimated results are not consistent with the theoretical expectations. None of the coefficients is 
statistically significant, except T-Bill rates. The statistically significant but negative coefficient of T-Bill indicates that one percent increase in interest rate decreases equity premium in the engineering sector by 0.05 percent. The rest of the variables in the model do not have any significant impact on the beverages sector. The possible reason may be the seasonal consumption pattern of beverages. Regardless of inflation, money supply, etc., people tend to use beverages in the summer and avoid in the winters.

The value of coefficient of determination $\left(R^{2}\right)$ indicates that more than 12 percent variation in the model is explained by the explanatory variables. Similarly, the value of adjusted$R^{2}$ implies that only 8 percent variation in equity premium is explained by the model. The value of F-statistics is statistically significant, which implies that the model fits the data well. Insignificant value of LM statistics indicates the absence of autocorrelation problem. In order to confirm the validity of the instrument, we find the value of J-statistics. The insignificant value of J-statistics shows that the instruments used in the analysis are valid.

4.5. Chemicals. Table 6D in the appendix presents the estimated results of chemical sector with macroeconomic variables. The estimated results are according to the theoretical expectations. The coefficient on market premium is positive and highly significant which indicates that one percent increase in market premium will increase equity premium in the chemical sector by 0.76 percent. The statistically significant negative coefficient on T-Bill rate indicates that one percent increase in interest rate decreases equity premium in the chemical sector by 0.02 percent. The negative and statistically significant coefficient of inflation indicates that one percent increase in inflation will decrease equity premium by 0.04 percent of chemical industry. This is consistent with the previous studies [54]. The statistically significant coefficients of industrial production and FDI indicate that for one percent increase in IDI and foreign direct investment, the equity premium of chemical sector will increase by 0.07 percent and 0.001 percent, respectively. The results are consistent with [23]. The negative statistically insignificant coefficient of money supply indicates that it does not have any statistically significant impact on the chemical sector.

The value of coefficient of determination $\left(R^{2}\right)$ indicates that more than 61 percent variation in the model is explained by the explanatory variables. Similarly, the value of adjusted$\mathrm{R}^{2}$ implies that more than 59 percent variation in equity premium is explained by the model. The value of F-statistics is highly statistically significant, which implies that the data are well fitted in the model. The value of the DW test is close to the expected value of 2, which confirms that there is serious problem of autocorrelation in the data. Insignificant value of LM statistics also confirms the absence of autocorrelation problem. Moreover, the highly statistically insignificant value of J-statistics indicates that the instruments used are valid.

4.6. Electrical and Engineering Goods. Table 6E in the appendix presents the estimated results of electrical and engineering sector with macroeconomic variables. The coefficient of market premium is positive, however, statistically insignificant, which indicates that the market premium does not affect the electrical and engineering sector. The statistically highly significant negative coefficient on $\mathrm{T}$-Bill rate indicates that one percent increase in interest rate decreases equity premium in the electrical and engineering sector by 0.09 percent. The negative and statistically significant coefficient of inflation indicates that one percent increase in equity premium of electrical and engineering sector decreases by 0.08 percent. The rest of the variables used in the model are not statistically significant. During the last one decade, the electrical and engineering sector was performing low because of the severe shortfall off energy in the country. This might be one of the reasons the macroeconomic variable is not showing any significant relationship with EE sector.

The value of coefficient of determination $\left(R^{2}\right)$ indicates that more than 9 percent variation in the model is explained by the explanatory variables. Similarly, the value of adjusted$R^{2}$ implies that more than 6 percent variation in equity premium is explained by the model. The value of the DW test is close to the desired value of 2 , which indicates the absence of autocorrelation problem. Insignificant value of LM statistics also confirms the absence of autocorrelation problem. Moreover, the high insignificant value of J-statistics shows that the instruments used in the analysis are valid.

4.7. Electricity. Table $6 \mathrm{~F}$ in the appendix presents the estimated results. The coefficient on market premium is positive and highly statistically significant which indicates that one percent increase in market premium will increase equity premium in the electrical industry by 0.90 percent. The statistically significant negative coefficient on T-Bill rate indicates that one percent increase in interest rate decreases equity premium in the chemical sector by 0.04 percent. The inflation has negative and statistically significant coefficients which indicate that one percent increase in inflation decreases equity premium of the electricity sector. This is consistent with the previous studies [54]. The statistical significant value of industrial production is consistent with the theoretical expectations that increase in industrial production causes an increase in the equity premium of electricity sector. One percent increase in industrial production increases ERP by 0.22 percent. The effect of FDI on equity premium is positive but statistically insignificant. Coefficient of money supply variable is also statistically insignificant, which implies that money supply does not affect equity premium in the electricity sector.

The value of coefficient of determination $\left(R^{2}\right)$ indicates that more than 29 percent variation in the model is explained by the explanatory variables. Similarly, the value of adjusted$R^{2}$ implies that more than 26 percent variation in equity premium is explained by the model. The value of F-statistics is statistically significant, which implies that it is well fitted in the model. The value of both DW test and LM statistics indicates the absence of autocorrelation problem. Insignificant value of LM statistics also confirms the absence of autocorrelation problem. Insignificant value of J-statistics indicates that the instruments used are valid. 
4.8. Food Producers. Table $6 \mathrm{G}$ presents the result for the food producer sector. The coefficient on market premium is positive and statistically significant which indicates that one percent increase in market premium will increase equity premium in the food industry by 0.40 percent. The statistically significant negative coefficient on T-Bill rate indicates that one percent increase in interest rate decreases equity premium in the food producer sector by 0.05 percent. The positive and statistically significant coefficients of foreign direct investment indicate one percent increase in FDI increases equity premium of the food producer sector by 0.05 percent. The inflation, industrial production, and money supply variables are statistically insignificant, which implies that these variables do not affect equity premium in the food producer sector.

The value of coefficient of determination $\left(R^{2}\right)$ indicates that more than 9 percent variation in the model is explained by the explanatory variables. Similarly, the value of adjusted$R^{2}$ implies that around 6 percent variation in equity premium is explained by the model. The values of the DW test and LM statistics indicate the absence of autocorrelation problem. Moreover, highly insignificant value of J-statistics shows that the instruments used in the analysis are valid.

4.9. Fixed Line Telecommunication. Table $6 \mathrm{H}$ in the appendix presents the estimated result of fixed line telecommunication sector. The coefficient on market premium is positive and statistically significant which indicates that one percent increase in market premium will increase equity premium in the electrical industry by 0.02 percent. The statistically significant negative coefficient on $\mathrm{T}$-Bill rate indicates that one percent increase in interest rate decreases equity premium in fixed line telecommunication sector by more than 0.05 percent. The positive and statistically significant coefficients of foreign direct investment indicate that one percent increase in FDI increases the equity premium of fixed line telecommunication sector by 0.05 percent. The inflation, industrial production, and money supply variables are statistically insignificant, which implies that these variables do not affect equity premium of the fixed line telecommunication sector.

The value of coefficient of determination $\left(R^{2}\right)$ indicates that more than 9 percent variation in the model is explained by the explanatory variables. Similarly, the value of adjusted$R^{2}$ implies that around 5 percent variation in equity premium is explained by the model. The values of the DW test and LM statistics indicate the absence of autocorrelation problem. Moreover, the highly insignificant value of J-statistics indicates that the instruments used in the analysis are valid.

The results and discussion for the next eight sectors are provided in the Appendix Section 2 and can be described in similar way.

\section{Conclusion}

Dynamics of equity premium are ranging from microlevel to macrolevel and proceeding further to some noneconomics phenomena. Awareness of the size of equity premium is an important number for the efficient allocation of funds. The statistics of equity premium for a particular security or a particular set of portfolio can be used for evaluating cost of equity as well as expected return. This part of the total returns has been extensively studied in developed as well as emerging equity markets. However, very limited literature is available for developing counties such as Pakistan, especially no study focused on Industry level equity premium. The author took a series of paper in this area to analyse and reached to forecast a suitable model. This part of the study explores the sectorial equity premium and macroeconomic variables as its determinants. We calculate the sector premiums for sixteen nonfinancial sectors.

Analyses are conducted using monthly equity prices data for the period of January 2001 to December 2018. As we know that macroeconomic are not controllable by the firms, however, change in these variables affects stock prices and the equity premium. The macroeconomic variables included in this study are interest rate, money supply, income (industrial production index), foreign direct investment, and inflation (consumer price index). Interest rate is the major component that greatly and directly affects the equity premium. Increase in interest rate leads to decrease in the equity premium as the equity premium is the difference between market return and risk-free rate of return. In this study, we use 3-month T-Bill rate (interest rate) as risk-free rate to calculate the equity premium.

For the analysis purpose, we proposed the extended version of macro-based multifactor model develop by [49] which includes more macroeconomic variables than the previous studies and we expand the estimation technique from simple regression to two-stage least square method. The model includes the market premium and five more macroeconomic variables which are more related to the capital market in general and to the nonfinancial sector in particular.

The impact of these macroeconomic variables also been examined on the equity premium of each nonfinancial sector. Due to the possible presence of endogeneity issue in the variables, we use two-stage least square (2SLS) method for estimation. The estimated results reveal that each single stock and each industry follow the bullish trend of the KSE100 index. If the market (KSE100 index) moves upward, regardless of the industry, most of the stock prices go up and increase the premium size which provides better returns than expected. The average equity premium of this study period ranges from -0.15 percent to 22.8 percent for nonfinancial sectors listed in PSX. The market premium is positive and highly significant in 14/16 sectors. The sectors which do not follow the market trend are beverages, food producing industry, and tobacco and the intuition is that these three industries are related to seasonal products. The sale of beverages increases in summer regardless of the market trend. Similarly, different food producing firms have peak sales in different seasons. Therefore, it does not have statistically significant relation with the market premium. Among the selected group of macroeconomic variables, change in interest rate effects all sector premium negatively followed by inflation in specific manufacturing sector. The 
industrial production, money supply, and foreign direct investment are positively related to different sectors according to the nature of their products and services.

Overall, based on these findings, we can formulate the investors must examine the size of equity premium and change in macroeconomic variables. Similarly, the investors need to invest in seasonal goods and services industries accordingly. Stable interest rate provides better returns. More foreign direct investments create healthy returns from investments in the stock market. The policy makers need to oversee the financial and economic policy to encourage investment in the stock market.

5.1. Practical and Theoretical Implications. Pakistan Stock Exchange is one the is emerging and changing behaviour markets with respect to the changes in macroeconomics and fiscal policies. The investors need to use a model which can capture the effect of company fundamental variables, macroeconomics behaviours, and noneconomic factors such as terrorism, political instability, and other related factors. For this purpose, we used macro-based multifactor model proposed for macroeconomic variables for examining the relationship of each or all variables. This can help to explain the variation of equity premium in Pakistan Stock Exchange. The investor also needs to examine the macroeconomic variables and its importance in investment decision. Interest rate, inflation, industrial production, money supply, and foreign direct investment are the variables that should be considered in asset pricing and investment decisions. The macro-based multifactor model used in this study can help the investor and institutions in examining the fluctuation in macroeconomics which leads to change in industry premium.

\section{Data Availability}

The data used to support the findings of this study are available from the corresponding author upon request.

\section{Additional Points}

Limitations of the Study. The scope of the study is limited only to the nonfinancial sector firms listed on Pakistan Stock Exchange. Pakistan Stock Exchange is an emerging south Asian capital market and the results are not compared with other emerging markets in the region. Financial structures of financial and nonfinancial firms are not the same; therefore, we consider only nonfinancial firms. Another limitation of the study is data constraint, as long-term data needed for the study are not available electronically. Hence, the study period is limited to 18 years only.

\section{Conflicts of Interest}

The authors declare that they have no conflicts of interest.

\section{Acknowledgments}

The authors take this opportunity to thank the Editor in Chief Prof. Baogui Xin for reviewing the paper and providing them more insightful comments. This research was supported by the National Social Science Fund (19BGL127), the National Natural Science Fund (71572071), the China Postdoctoral Science Foundation funded project (2015M571708), the Humanities and Social Sciences Fund of the Ministry of Education (18YJA630074), and Ministry of Education of the Republic of Korea and the National Research Foundation of Korea (NRF-2019K2A9A2A06024410) and partial support from ILMA University, Karachi, Pakistan.

\section{Supplementary Materials}

The appendixes contain all the resulted tables of the study. (Supplementary Materials)

\section{References}

[1] R. Mehra and E. Prescott, "The equity premium in retrospect," NBER Working Paper, 9525, National Bureau of Economic Research, Cambridge, MA, USA, 2003.

[2] A. Damodaram, Equity Risk Premiums (ERP): Determinants, Estimation and Implications-The 2012, Elsevier, Amsterdam, Netherlands, 2012.

[3] J. D. Shackman, "The equity premium and market integration: evidence from international data," Journal of International Financial Markets, Institutions and Money, vol. 16, no. 2, pp. 155-179, 2006.

[4] S. N. Erbas and A. Mirakhor, "The equity premium puzzle, ambiguity aversion, and institutional quality," International Monetary Fund Working Paper, pp. 7-230, IMF, Washington, DC, USA, 2007.

[5] M. Imran, "Company fundamentals as determinants of firmlevel equity premiums: evidence from an emerging economy," Panoeconomicus, pp. 1-13, 2020.

[6] H. Markowitz, "Portfolio selection," The Journal of Finance, vol. 7, no. 1, pp. 77-91, 1952.

[7] J. L. Treynor, "Market value, time, and risk," 1961.

[8] W. F. Sharpe, "Capital asset prices: a theory of market equilibrium under conditions of risk," The Journal of Finance, vol. 19, no. 3, p. 425, 1964.

[9] J. Lintner, "The valuation of risk assets and the selection of risky investments in stock portfolios and capital budgets," The Review of Economics and Statistics, vol. 47, no. 1, pp. 13-37, 1965.

[10] J. Mossin, "Equilibrium in a capital asset market," Econometrica, vol. 34, no. 4, pp. 768-783, 1966.

[11] E. F. Fama and K. R. French, "The capital asset pricing model: theory and evidence," Journal of Economic Perspectives, vol. 18, no. 3, pp. 25-46, 2004.

[12] A. Damodaram, Equity Risk Premiums (ERP): Determinants, Estimation and Implications-The 2016, Elsevier, Amsterdam, Netherlands, 2016.

[13] T. Choudhry and H. Wu, "Forecasting ability of GARCH vs Kalman filter method: evidence from daily UK time-varying beta," Journal of Forecasting, vol. 27, no. 8, pp. 670-689, 2008.

[14] M. A. Bellelah, M. O. Bellelah, H. Ben Ameur, and R. Ben Hafsia, "Does the equity premium puzzle persist during financial crisis? The case of the French equity market," Research 
in International Business and Finance, vol. 39, no. 1, pp. 851-866, 2016.

[15] E. Ahmed and J. B. Rosser Jr., "Non-linear speculative bubbles in the pakistani stock market," Pakistan Development Review, vol. 34, no. 1, pp. 25-41, 1995.

[16] F. Hussain, "The day of the week effect in the Pakistani equity market: an investigation," The Lahore Journal of Economics, vol. 5, pp. 22-37, 2000.

[17] A. Hassan and M. T. Javed, "An empirical investigation of the causal relationship among monetary variables and equity market returns," Lahore Journal of Economics, vol. 14, no. 1, pp. 115-137, 2009.

[18] Abbas, "From regular-beta CAPM to downside-beta CAPM," European Journal of Social Sciences, vol. 21, no. 2, pp. 189-203, 2011.

[19] M. Zeeshan and Abdullah, "Capital asset price model empirical evidence from karachi stock exchange," Journal of Research in Business and Management, vol. 4, no. 10, pp. 61-67, 2016.

[20] E. Ahmad and A. Y. Javid, “Testing multifactor capital asset pricing model in case of Pakistani market," International Research Journal of Finance and Economics, vol. 25, pp. 114-123, 2008.

[21] M. Hanif, "Testing Application of CAP Model on KSEPakistan: A Case Study on Tobacco Sector," Management Accountant March 2010 Issue, Elsevier, Amsterdam, Netherlands, 2010, http://ssrn.com/abstract=1494906SSRN:.

[22] A. Hassan and M. T. Javed, "Size and value premium in Pakistani equity market," African Journal of Business Management, vol. 5, no. 16, pp. 6747-6755, 2011.

[23] M. Imran and Abbas, "The relationship between macroeconomic variables and cement industry returns: empirical Evidence from Pakistani Cement Industry," International Journal of Research in Commerce, IT and Management, vol. 3, no. 3, pp. 10-17, 2013.

[24] A. Hassan and M. T. Javed, "Illiquidity premium and stylized equity returns," The IUP Journal of Financial Economics, vol. 1, pp. 41-52, 2011.

[25] M. Imran, Y. Zhong, and H. C. Moon, "Nexus among foreign remittances and economic growth indicators in south Asian countries: an empirical analysis," Korea International Trade Research Institute, vol. 17, no. 1, pp. 263-275, 2021.

[26] E. F. Fama and K. R. French, "The equity premium," The Journal of Finance, vol. 57, no. 2, pp. 637-659, 2002.

[27] M. Lettau, S. C. Lundvigson, and J. W. Wacher, "The declining equity premium: what role does macroeconomic risk play?" The Review of Financial Studies, vol. 21, 2007.

[28] E. F. Fama and G. W. Schwert, "Asset returns and inflation," Journal of Financial Economics, vol. 5, no. 2, pp. 115-14610, 1977.

[29] D. B. Keim and R. F. Stambaugh, "Predicting returns in the stock and bond markets," Journal of Financial Economics, vol. 17, no. 2, pp. 357-390, 1986.

[30] M. W. Brandt and Q. Kang, "On the relationship between the conditional mean and volatility of stock returns: a latent var approach," Journal of Financial Economics, vol. 72, no. 2, p. 21710, 2004.

[31] Y. Li and T. Anthony, "The role of macroeconomic and policy uncertainty in density forecast dispersion," Journal of Macroeconomics, vol. 67, Article ID 103266, 2021.

[32] Z. Wang, "A shrinkage approach to model uncertainty and asset allocation," Review of Financial Studies, vol. 18, no. 2, pp. 673-705, 2005.
[33] R. Kizys and P. Spencer, "Assessing the relation between equity risk premium and macroeconomic volatilities in the UK," 2007, http://www.qass.org.uk/2008/vol2_1/paper3.

[34] O. A. Lamont, "Economic tracking portfolios," Journal of Econometrics, vol. 105, no. 1, pp. 161-184, 2001.

[35] C. Neely, D. Rapach, J. Tu, and G. Zhou, "Forecasting equity risk premium," 2011, http://papers.ssrn.com/sol3/papers.cfm? abstract_id=1568267.

[36] P. Chou, W.-S. Li, S. Rhee, and J.-S. Wang, "Do macroeconomic factors subsume anomalies in long investment horizons?," 2007, http://www.emeraldinsight.com/journals.htm? articleid $=1621158$ \&show $=$ html.

[37] W. Mengyun, M. Zakaria, Z. Linrong, M. U. Farooq, and S. K. Muhammad, "Terrorism and political instability on equity premium: evidence from Pakistan," Physica A: Statistical Mechanics and Its Applications, vol. 492, pp. 17531762, 2018.

[38] M. Imran, M. Wu, L. Zhang, Q. He, and A. Yar, "An empirical analysis of firm specific factors and equity premium: evidence from manufacturing sector of Pakistan," Mathematical Problems in Engineering, vol. 2020, Article ID 1346053, 9 pages, 2020.

[39] J. Tobin, "Liquidity preference as behavior towards risk," The Review of Economic Studies, vol. 25, no. 2, pp. 65-86, 1958.

[40] E. J. Elton and M. J. Gruber, Modern Portfolio Theory and Investment Analysis, Wiley, New York, NY, USA, 5th edition, 1995.

[41] W. N. Goetzmann and R. G. Ibbotson, The Equity Risk Premium: Essays and Explorations, Oxford University Press, Oxford, UK, 2006.

[42] E. Elton, Modern Portfolio Theory and Investment Analysis, Wiley, New York, NY, USA, 8th edition, 2011.

[43] P. Fernandez, A. O. Pizarro, and I. F. Acin, Market Risk Premium used in 71 countries in 2016: A Survey with 6932 Answers, Elsevier, Amsterdam, Netherlands, 2016, https:// papers.ssrn.com/sol3/papers.cfm?abstract_id=2776636.

[44] R. Roll and S. A. Ross, "On the cross-sectional relation between expected returns and betas," The Journal of Finance, vol. 49, no. 1, pp. 101-121, 1994.

[45] R. D. Arnott and R. D. Henriksson, "A disciplined approach to global asset allocation," Financial Analysts Journal, vol. 45, pp. 17-28, 1989.

[46] M. Imran, M. Wu, S. Gu, S. Saud, and M. Abbas, "Influence of economic and non-economic factors on firm level equity premium: evidence from Pakistan," Economics Bulletin, vol. 39, no. 3, 2019.

[47] A. S. Churchill, S. L. Yew, and M. Ugur, "Does government size affect per-capita income growth? A Hierarchical metaregression analysis," Economic Record, vol. 93, no. 300, pp. 142-171, 2015.

[48] J. Bai, "Equity premium predictions with adaptive macro indices," SSRN Electronic Journal, 2008, https://www. newyorkfed.org/research/staff_reports/sr475.html.

[49] N.-F. Chen, R. Roll, and S. A. Ross, "Economic forces and the stock market," The Journal of Business, vol. 59, no. 3, pp. 383-403, 1986.

[50] G. Connor, "The three types of factor models: a comparison of their explanatory power," Financial Analysts Journal, vol. 51, no. 3, pp. 42-46, 1995.

[51] C. Ewijk, H. L. F. De Groot, and A. J. Santing, "A metaanalysis of the equity premium," Journal of Empirical Finance, vol. 19, no. 5, pp. 819-830, 2012.

[52] J. M. Wooldridge, Econometric Analysis of Cross Section and Panel Data, MIT Press, Cambridge, MA, USA, 2002. 
[53] L. F. Ferreira, Macroeconomic determinants of premium implicit in market risk in Brazil, Master's Dissertation in Economics, Insper, São Paulo, Brazil, 2011.

[54] K. B. Luintel and K. Paudyal, "Are common stocks a hedge against inflation?” Journal of Financial Research, vol. 29, no. 1, pp. 1-19, 2006. 